Four neonatal deaths occurred. In one pregnancy undiagnosed twins were delivered weighing $3 \mathrm{lb} .3 \mathrm{oz}$. (1,445 g.) and 2 lb. 13 oz. $(1,275$ g.). They survived only a short time. In another the baby died of pneumonia 12 hours after delivery. The fourth breathed for a short time but died very soon after birth. Post-mortem examination showed evidence of longstanding haemolysis with generalized bile-staining, but no cause for this could be found. Of the remaining 47 babies, 29 cried at birth and 18 had blue asphyxia and required resuscitation.

All patients were given routine oxytocics. There were two post-partum haemorrhages, each of $40 \mathrm{oz}$. (1,140 ml.). Both were due to failure of the uterus to contract.

\section{Discussion}

Rheomacrodex is a dextran with an average molecular weight of 40,000 . It acts by decreasing the viscosity of blood, preventing intravascular sludging, and by this means the supply of blood through the small vessels is improved. Temporary expansion of plasma volume takes place, and it should be used carefully in patients with cardiac disease. Care should also be taken to prevent leakage from the vein, as this will cause local oedema; and use of the drug is contraindicated in thrombocytopenia, pulmonary oedema, and sepsis.

It has been shown in open heart surgery (Breckenridge and Walker, 1963) that if the amount of Rheomacrodex given exceeds $20 \mathrm{mg} . / \mathrm{kg}$. of body weight there is increased operative bleeding, though there is no evidence that any increase occurs in the amount of post-operative bleeding. In this series a small dose was used, as the effect of prolonged treatment cannot be studied when the foetus shows signs of distress.

The effect of Rheomacrodex on blood-clotting mechanisms shows no abnormality directly attributable to the substance (Breckenridge and Walker, 1963) and, unlike dextran, the substance has no effect on cross-matching blood (Powley, 1963). Our study was marred by the maternal death. Pulmonary embolism occurring 24 hours after caesarean section is unusual.
There is no reason to suppose this was brought on by the treatment. Had the Rheomacrodex been given earlier to this patient and in a bigger dose, it is possible that by preventing venous stasis thrombosis would not have occurred.

The success of Rheomacrodex in alleviating the distress in these 41 cases makes it useful to the practising obstetrician, though a much larger series will have to be completed before a full assessment of its value can be made.

\section{Summary}

An attempt to improve the blood supply to the placental site by the fairly rapid infusion of $10 \%$ Rheomacrodex in dextrose is described. Its use in 50 cases of foetal distress in labour resulted in alleviation of the distress in 41 cases, 37 within one hour of starting the infusion.

There was one maternal and four neonatal deaths, but all of these were unconnected with the treatment. Two post-partum haemorrhages occurred, both due to failure of the uterus to contract.

There are few contraindications to the treatment, and these are outlined. A further large series will have to be completed before the full value of the drug can be assessed.

I would like to thank Mr. J. M. Scott and Mr. R. G. Law for allowing me to study patients under their care, and Sister M. E. T Surridge and her staff for their most helpful co-operation.

\section{REFERENCES}

Bergentz, S. E., Gelin, L. E., Rudenstam, C. M., and Zederfeldt, B. (1961a). Buil Soc. int. Chir., 20, 623 Bienenstock, J., and Harding, E. L. T. (1964). Lancet, 1, 524 Breckenridge, I. M., and Walker, W. F. (1963). Ibid., 1, 1190. Gelin, L. E. (1961). Acta chir. scand., Suppl. 210, p. 1. - and Ingelman, B. (1961). Ibid., 122, 294.

Leak, D and Kemball Price, R. (1964). Lancet, $1,772$.

. W. (1961). Surgery, 50, 12 .

Powley, P. H. (1963). Lancet, 1, 1189

Ratliff, A. H. C. (1963). Ibid., 1, 1188

\title{
A New Effective Diuretic-Lasix
}

\author{
WILFRED STOKES, * M.D., M.R.C.P. ; L. C. A. NUNN, † PH.D.
}

Brit. med. F., 1964, 2, 910-914

One of the diuretics containing the metadisulphamoyl group in the benzene ring, 4-chloro- $N$-(2-furyl-methyl)-5-sulphamoyl anthranilic acid (Lasix), has been tried intensively on the Continent and in America under the name of Fursemide. Experience of this preparation over 22 months and with more than 80 patients is now reported, the trial substance in the United Kingdom having been known as Salu 058, now available commercially as Lasix (Fig. 1).

\section{Previous Studies}

Preliminary animal studies with Lasix showed very safe margins of tolerance, with a diuretic response superior to that

\footnotetext{
- From the Department of Medicine, Stoke Mandeville Hospital, Aylesbury.
rom the Department of Pathology, Stoke Mandeville Hospital, From the
Aylesbury.
}

obtained with hydrochlorothiazide. Concentrations can be determined fluorometrically down to a concentration of 0.01 $\mu \mathrm{g} . / \mathrm{ml}$., and to some extent Lasix appears in the urine of man unchanged. Labelled with ${ }^{55} \mathrm{~S}$ and given to rats, 25 to $30 \%$ of the radioactivity was eliminated through the kidneys and $60 \%$ through the faeces (Reports from Hoechst Laboratories at Symposium on Fursemide, 1963).

Suzuki, Klutsch, and Heidland ${ }^{3}$ in experiments on dogs showed an increase of sodium and potassium rejection in the<smiles>[R16]c1cc(S(N)(=O)=O)c(Cl)cc1NCc1ccco1</smiles><smiles>NOS(=O)(=O)c1cc2c(cc1Cl)NCNS2</smiles>

HYDROCHLOROTHIAZIDE

FIG. 1 
proximal tubule, while in the distal tubule a decrease of the sodium reabsorption and a secretion of potassium were demonstrated. There was no influence on the para-aminohippuric acid (PAH) secretion.

Deetzen, ${ }^{1}$ in a micropuncture study on single nephrons of cat kidneys, concluded that this drug decreased the sodium reabsorption in the proximal tubule by $30 \%$, and another site of the action of Lasix seemed to be in the loop of Henle, probably in the thick ascending limb. Again no inhibiting effect on the PAH transport could be demonstrated.

Josephson $^{1}$ studied the PAH, inulin, and creatinine clearances after intravenous dosage of Lasix to healthy and pyelonephritic human subjects, the renal vein being catheterized in ane. His results indicated that the reabsorption of water, sodium, and chloride was not only depressed in the distal tubule but also in the proximal convolution. According to Bekaert ${ }^{1}$ the urinary excretion of sodium was more significant than the potassium loss in cases of nephrotic and cardiac oedema, and the decrease of plasma-sodium concentration was proportionately more pronounced than that of plasma potassium.

Hutcheon, Mehta, and Leonard (1964) reported an increased renal sodium, potassium, and chloride excretion and urine volume in patients with congestive heart failure. The duration of the diuretic response was limited to a period of 6 to 12 hours. This response to Lasix was due to increased formation of a concentrated urine, demonstrated by an increase in osmolal clearance. The results support the view that in part this is due to inhibition of sodium reabsorption in the distal diluting sites of the nephron. After completion of the natriuretic response patients formed a dilute urine. When the drug was given once daily, this alternating pattern of intervals of increased osmolal clearance followed by periods of increased solute-free water clearance was observed throughout the period of Lasix therapy. Endogenous creatinine-clearance rates and plasma-electrolyte concentrations remained within normal limits, but Lasix was found to have a significantly greater therapeutic efficacy than hydrochlorothiazide when the drugs were given over a period of one week at maximal therapeutic dose levels (Hutcheon ${ }^{1}$ ). An occasional increase of blood-uric-acid concentrations reported by that author has been confirmed by Kuhlback. ${ }^{1}$ No interference with glucose metabolism has been reported.

Reubi and Cottier (1961) demonstrated that when glomerular filtration is reduced to $10-15 \mathrm{ml}$./minute diuretics did not increase sodium elimination nor diuresis. Vorburger (1964) found, however, that Lasix promoted a satisfactory natriuresis even when renal function was impaired, not only through inhibition of reabsorption in the proximal tubules but also because it increased glomerular filtration. From ionograms he concluded that the tubular effect resembles that of the mercurial diuretics. Klutsch, Heidland, and Suzuki (1964) remarked that a unique action of Lasix consisted in an increase in diuresis even in patients with filtration rates between 10 and $20 \mathrm{ml} . /$ minute. Kiessling (1964), in studies of Lasix in 102 cases, including two patients with amyloid nephrosis, obtained a diuretic response with blood urea levels up to 140 $\mathrm{mg} . / 100 \mathrm{ml}$.

Vorburger $^{1}$ found an increase of inulin clearance, above all in cases of advanced renal failure. This he could explain only by an increase of glomerular filtration rate, which, with unchanged cardiac output and heart rate, would imply a decrease of preglomerular vascular resistance.

Schirmeister ${ }^{1}$ reported that the diuretic effect was shown to begin within five minutes of intravenous administration even in patients with a pronounced reduction of glomerular filtration rate and renal plasma flow, and he therefore concluded that this drug, given by the intravenous route, would prove useful for the treatment of acute pulmonary oedema.

Studying the transport of ions across cellular membranes by the method of Ussing (1949) and Ussing and Zerahn (1951),
Karger and Nagel (1964) found that, contrary to hydrochlorothiazide and mercurial diuretics, Lasix caused a distinct rise in potential without variation of the short-circuit current. It was concluded that Lasix lowers the permeability of cell membranes for anions, and thereby possibly develops an antagonistic effect on the antidiuretic hormone.

The value of combining Lasix with anti-aldosterone preparations in chronic cases of oedema was mentioned by Wolff and Kruck, ${ }^{1}$ by Jansen, ${ }^{1}$ and by Vorburger (1964). Kleinfelder (1963) found that the logarithmic dose-effect curve obtained in healthy persons (dose plotted against increase in sodium excretion) is not linear, as it is with thiazide compounds, but follows a steepening upward curve, the course of which is confirmed by regression calculations. The same curve against increase in potassium excretion, however, is linear. He therefore postulated that further diuresis would result from doses higher than the $100 \mathrm{mg}$. already tested. In the case of hydrochlorothiazide $150 \mathrm{mg}$. produced less sodium excretion than 100 mg. (Richterich, 1959). Kleinfelder (1963) considered Lasix distinctly superior in diuretic action, fluid output being $200 \%$ greater and sodium excretion $167 \%$ greater than the levels obtained with hydrochlorothiazide.

\section{Management of Present Clinical Trial}

The variable and changing factors in the oedematous state which influence the response to diuretics seldom allow simple comparisons or identical subjects as controls. Rebound phases are known to occur after diuresis, when transfer of fluid and electrolytes may continue from the extravascular tissues to the circulation. In order to avoid such rebound influence, at least one day was usually interposed between the different preparations compared; and comparisons were repeated, the patient being his own control when oedema and other variables were judged clinically constant, with due regard to influencing factors such as renal efficiency, serum proteins, electrolytes, etc. The maximum test of a new diuretic, however, is the challenge of a patient in anasarca when other proved diuretics have failed. Success in five such instances is included in our experience.

Dosage is largely arbitrary, governed by limits of known safety, experience, and recommendation. At the end of 1962 it was not known that larger doses of the trial substance (Salu 058) had been safely used elsewhere ; accordingly small doses of 25 and $50 \mathrm{mg}$. were assessed against similar dosage of hydrochlorothiazide. Later, doses of Lasix were effectively given up to $300 \mathrm{mg}$., but the maximum dosage of comparative oral diuretics used was $100 \mathrm{mg}$. for hydrochlorothiazide, $200 \mathrm{mg}$. for chlorthalidone, and $5 \mathrm{mg}$. for bendrofluazide, while $2 \mathrm{ml}$. intramuscularly was always used in the case of mersalyl.

Although without the strict facilities of a metabolic unit, it was arranged that restricted sodium intake and potassium content of the diet were approximately constant, fluid intake and outputs were recorded, and also changes in weight when practicable. A close watch was kept for side-effects, subjective, haematological, and biochemical. In suitable cases electrolytes were studied in the blood and urine before, during, and after the diuretic phase.

Sodium and potassium concentration after Lasix administration was studied in hourly urine volumes in 12 patients, as also during a similar period the previous day without diuretics.

The following is based on our experience in over 80 oedematous patients, in the main suffering from congestive cardiac failure of various causation, and including four with hepatic cirrhosis and ascites, and two out-patients with premenstrual sodium retention.

\section{Clinical Results}

Although in a few cases of congestive heart failure with oedema which responded readily to diuretics there was little 
difference between the urinary output in the 24 hours following Lasix and hydrochlorothiazide in low dosage ( 25 and $50 \mathrm{mg}$.), in the vast majority a better response was obtained with the former (Fig. 2). Similarly, Lasix in 50-mg. dosage proved more efficient than chlorthalidone (200 mg.) (Fig. 3) and bendro-

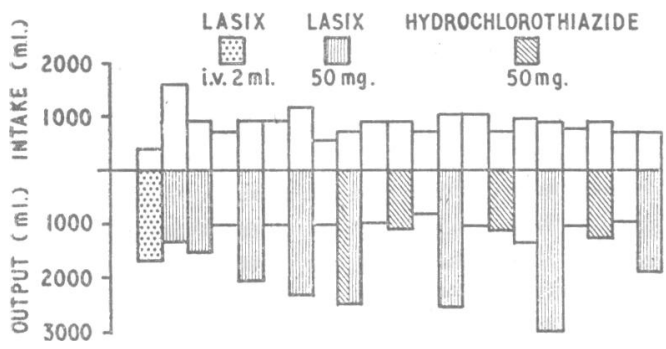

Fig. 2.-Comparison of diuretic res-onse to Lasix $50 \mathrm{mg}$. by mouth and to hydrochlorothiazide $50 \mathrm{mg}$. in a case of chronic congestive heart failure.

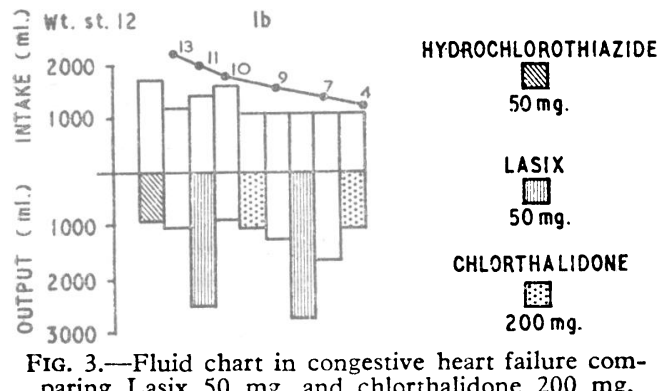

fluazide ( 5 mg.) (Fig. 4) in the few cases so compared. When larger urinary outputs were required no advantage was found in combining Lasix with a thiazide compound; but a larger cose of Lasix was then indicated-up to $300 \mathrm{mg}$. in our series. After Lasix given by mouth in the average patient, diuresis (without an indwelling catheter) begins within one hour and continues for three to five hours. The intravenous route shows some urinary response within 30 minutes, and the main effect is over in one and a half to four hours, depending on the dose

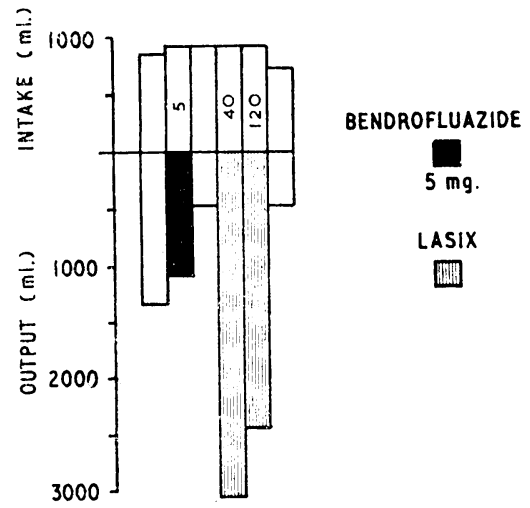

FIg. 4.-Comparative urinary output to bendrofluazide $5 \mathrm{mz}$. and Lasix $40 \mathrm{mg}$. in a case of congestive heart failure. (The dose of $120 \mathrm{~ms}$. proved unnecessarily large and $40 \mathrm{mg}$. would have sulficed for this man's degree of fluid retention.)

given. Potassium loss during diuresis due to Lasix was proportionately less than with other diuretics investigated.

The following case histories illustrate several points.

Case 1.-A man of 53 was admitted to hospital in anasarca with cor pulmonale, following 20 years of chronic bronchitis. The electrocardiogram showed $p$ pulmonale and right ventricular preponderance. His blood-pressure was $150 / 85$. Proteinuria was slight. Radiographically a large emphysematous bulla was present at the left base with a depressed diaphragm, and innumerable lines of Kerley were seen at both bases. (Hb was $94 \%$; blood urea
$77 \mathrm{mg} . / 100 \mathrm{ml}$; $\mathrm{Na} 150, \mathrm{~K} 3.3, \mathrm{Cl} 90$, and $\mathrm{HCO}_{3} 37.5 \mathrm{mEq} / \mathrm{l}$.) Mersalyl ( $2 \mathrm{ml}$. intramuscularly) caused little or no diuresis, even with spironolactone (Aldactone $\mathrm{A}$ ) and later dichlorphenamide; neither did Lasix $120 \mathrm{mg}$. by mouth. During the four weeks after admission he improved with several measures, including drainage by Southey's tubes, and his blood urea fell to normal. Mersalyl, $2 \mathrm{ml}$. intramuscularly, now resulted in a slight improvement in output $(580 \mathrm{ml}$. over intake), but two days later Lasix, $60 \mathrm{mg}$. intravenously, and one hour later $120 \mathrm{mg}$. orally, was followed by an output of $3,050 \mathrm{ml}$. of urine, and excellent responses were then maintained with Lasix.

Case 2.-A diabetic man of 72 was admitted to hospital with anasarca, bilateral pleural effusions, and gross engorgement of his jugular veins and liver. An old antero-septal infarct was combined with right ventricular stress from pulmonary emphysema and chronic bronchitis. His blood-pressure was $130 / 80$, his blood urea $60 \mathrm{mg} . / 100 \mathrm{ml}$., and the serum electrolytes and diabetic state were well controlled ( $\mathrm{Na} 141, \mathrm{~K} 4.8, \mathrm{Cl} 97 \mathrm{mEq} / \mathrm{l}$. ; blood sugar $143 \mathrm{mg} . / 100 \mathrm{ml}$; $\mathrm{Hb} 103 \%$; serum albumin 3, globulin 2.5 g./ $100 \mathrm{ml}$.). A trace of albumin was present in his urine. At home he had gradually become resistant to treatment with digitalis, lowsalt diet, and diuretics, including mersalyl $(2 \mathrm{ml}$. intramuscularly) and hydrochlorothiazide in larger dosage (100 mg.). His first improvement in output resulted from $25 \mathrm{mg}$. of Lasix intravenously. Satisfactory outputs over four days with $100 \mathrm{mg}$. and $150 \mathrm{mg}$. of Lasix by mouth daily were then followed by diminishing diuresis, until the addition of spironolactone $25 \mathrm{mg}$. t.i.d. (Fig. 5). Hydrochlorothiazide in doses of $100 \mathrm{mg}$. was then tried once again combined with spironolactone, but without benefit; however, a subsequent return to larger doses of Lasix up to $225 \mathrm{mg}$. by mouth resulted in outputs up to $3,300 \mathrm{ml}$. when the anti-aldosterone preparation had been discontinued.

In this case, as in two others, it did seem that the antialdosterone preparation was of temporary assistance ; but under these circumstances reliance on increasing the dosage of Lasix became our normal rule.

Case 3.-Experience with another man in chronic congestive heart failure secondary to a former severe myocardial infarct and pulmonary emphysema indicated no advantage in dividing a daily dose into three. A larger urinary output was obtained by the one single administration in the morning (Fig. 6). When diuretic responses of approximately 4 litres were obtained with doses of $225 \mathrm{mg}$. the serum potassium fell below $3 \mathrm{mEq} / \mathrm{l}$. Subsequently potassium chloride (effervescent tablets, $4-6 \mathrm{~g}$. in 24 hours) was given as a routine to this patient, as to any whose urinary output exceeded 2 litres. This is particularly important when potassium depletion is likely after long periods of treatment for chronic heart failure, although serum levels may be normal. Potassium supplements add a diuretic influence (Taylor and Faloon, 1959 ; Spencer, 1959 ; Scott, Emanuel, and Haddy, 1959).

Case 4.-A man of 45 was admitted to hospital after a diffuse anterior myocardial infarct in sinus rhythm and severe congestive heart failure. He was orthopnoeic, with diffuse crepitations throughout his lungs, and was coughing up a thin frothy sputum. Lasix $20 \mathrm{mg}$. was given intravenously. Within one and a half hours his cough and sputum had ceased and his lungs on auscultation were remarkably cleared following an excellent but unmeasured urinary output.

The greatest diuresis recorded in our series was $6,735 \mathrm{ml}$. against a fluid intake that day of $1,260 \mathrm{ml}$. (Fig. 7), a response to a single dose of $200 \mathrm{mg}$. Lasix. The optimum dose (although not necessarily the maximum diuresis, which might not be to the best advantage of the patient) seems to lie between 80 and $240 \mathrm{mg}$. for moderate and severe cases of congestive heart failure. The tablets originally supplied for trial in 1962 contained $25 \mathrm{mg}$., and later $40 \mathrm{mg}$., which dosage seems satisfactory for long-term treatment of mild chronic cardiac insufficiency and uncomplicated hypertension, and also for short terms in premenstrual sodium retention.

The efficiency of this new diuretic makes any unwarranted large dosage unnecessary and perhaps dangerous. If dehydration and electrolyte depletion are to be avoided the optimum effective dosage must be adjusted to the clinical state. The long-term prescription of small doses, such as $40 \mathrm{mg}$. on alternate mornings, seems safe with occasional checks on serum- 
potassium levels. Observations on out-patients for periods of three and four weeks with this regimen showed no fall in serum potassium; but although hypokalaemia may be less likely with Lasix than with any diuretics of the thiazide group slow depletion from the body may become evident only after longer observation. Routine potassium supplements seem essential with the larger doses of Lasix, and should the manu- content, and citrus fruits or other substances of high potassium content were not allowed. In two instances the serum potassium was found to rise under low Lasix dosage, and the only explanation for this was discovered in an inadvertent "salt substitute" given to those patients. After repeated but moderate dosage an elderly man with previous known psychopathic tendencies became agitated, with delusions of persecution. By next

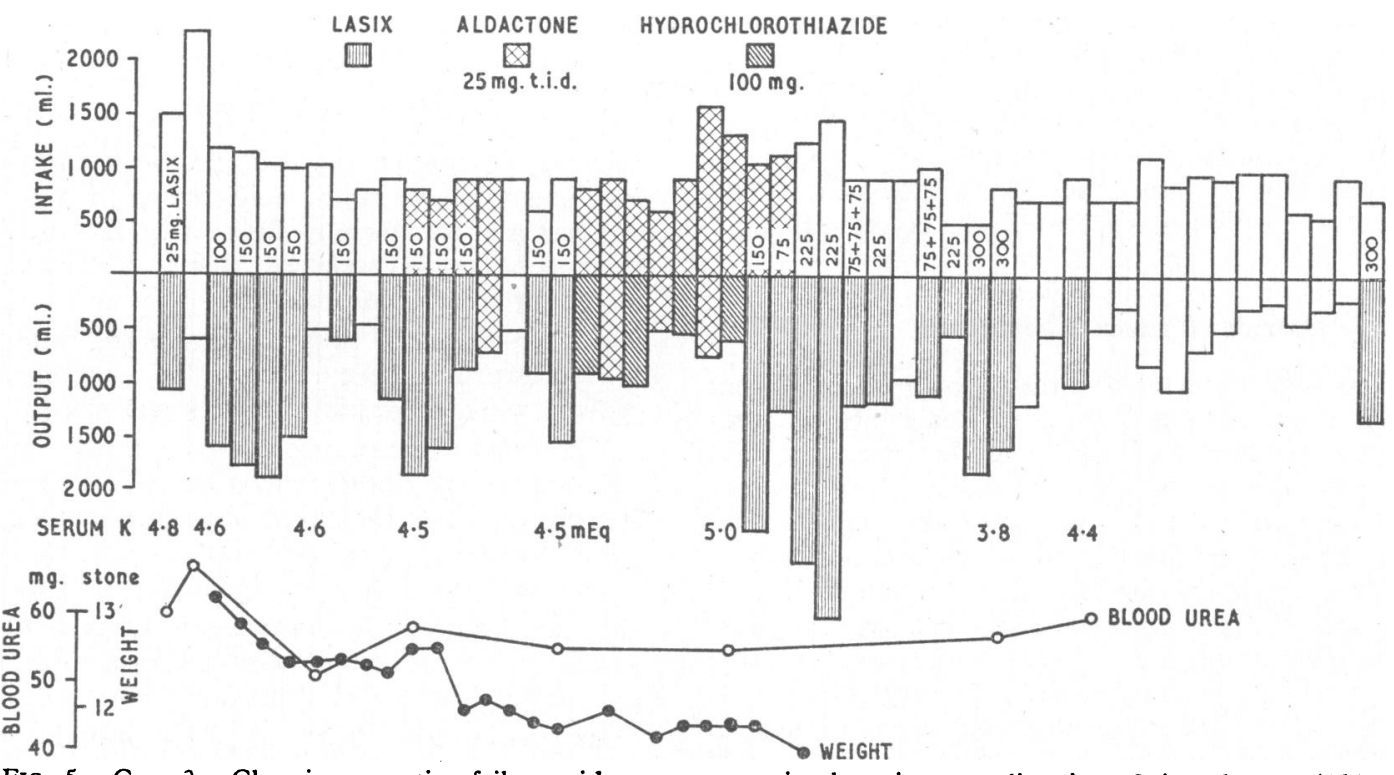

FIG. 5.-Case 2. Chronic congestive failure with anasarca previously resistant to diuretics. Spironolactone (Aldactone $\mathrm{A}$ ) in combination with Lasix in dosage up to $300 \mathrm{mg}$. relieved his oedema.

facture of larger tablets be contemplated potassium might be incorporated with advantage.

Studies of the fluid and electrolyte output during the diuretic response to Lasix in 12 of our series support a statement that the isotonicity of the urine is broadly maintained. The sodium excretion in terms of absolute output roughly follows the volume increase in urine. The potassium ( $\mathrm{mEq} / \mathrm{l}$.) is proportionately less, but still is increased during the diuretic phase, although the tonicity of the urine remains roughly the same. No compensatory phases of dilute urine were recorded. In the 24-hour urine studies following Lasix the potassium discharged was definitely less than that after hydrochlorothiazide.

Although our observations were without the discipline of a metabolic ward, the diet was standardized for low-sodium morning, when his electrolytes were examined, normal levels were found. In retrospect the transient state was considered to be hypokalaemic. Potassium supplements were subsequently given as a routine measure, with no relapses in his mental state. Otherwise among our in-patients without hepatic disorder no fall in serum potassium was noted except after large doses and massive outputs. In one case symptoms of gout were provoked, although routine estimations of uric acid were not performed.

\section{Hypokalaemia and Liver Disease}

One jaundiced man with oedema and ascites in chronic liver failure from hepatic cirrhosis improved rapidly, losing the

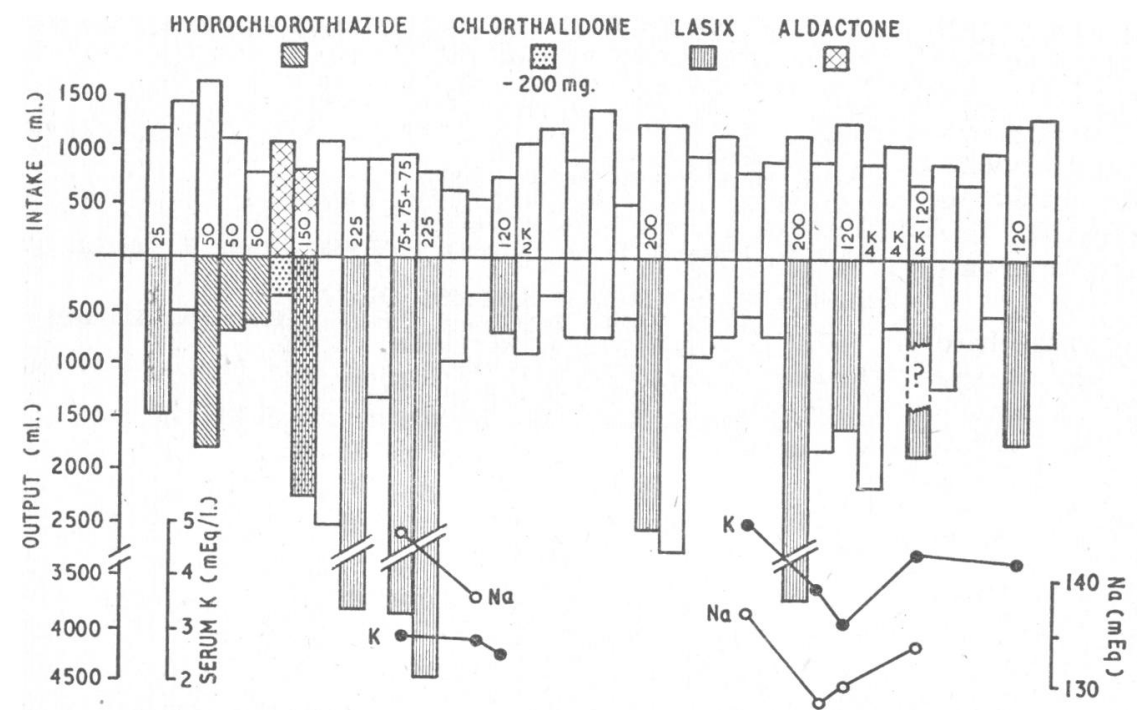

FIG. 6.-Case 3. Hypokalaemia resulting from massive urinary output following Lasix in doses up to $225 \mathrm{mg}$. and inadequate potassium intake. Divided dosage showed no advantage over one dose of equal total amount.

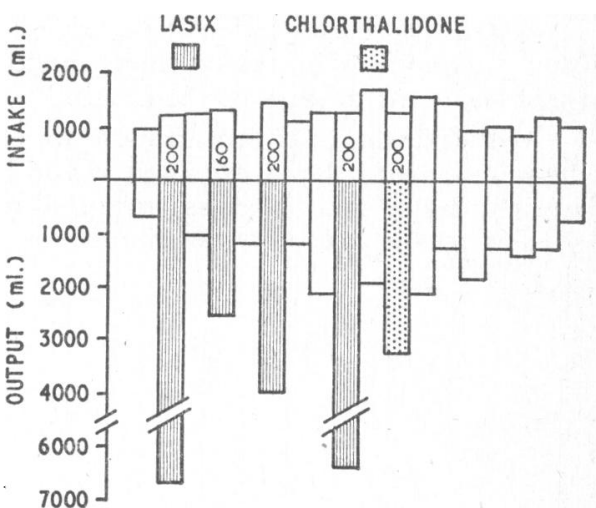

FIG. 7.-Diuresis of $6,735 \mathrm{ml}$. to Lasix 200 mg. with no ill effect. Potassium supplements are required in cases so responding. 
greater part of his fluid retention within a week. He was receiving $50 \mathrm{mg}$. of Lasix each morning without potassium supplement. In spite of factors of anaemia and hypoproteinaemia, over 18 litres of urine were passed in the seven days, which brought his seium potassium down to $3.5 \mathrm{mEq} / 1$. Under relaxed supervision a further sudden fall was inadvertently caused by a three-day period with hydrochlorothiazide (50 mg.). A return of flapping tremor and hallucinations responded rapidly to potassium, the serum level having fallen to $2.6 \mathrm{mEq} / 1$. This demonstrated the effect of hypokalaemia on the failing liver and the dangers of Lasix as with hydrochlorothiazide for such patients, particularly without adequate potassium supplements (Sherlock and Shaldon, 1963). By this precaution hypokalaemia was avoided in the three other cases of hepatic cirrhosis with ascites, which responded wcll to Lasix as regards fluid loss.

\section{Parenteral Lasix Therapy}

The indications for parenteral administration are few. From our records it is estimated that $25 \mathrm{mg}$. of Lasix intravenously causes a response quantitatively similar to that from mersalyl (2 ml. intravenously) but far more rapidly. The prompt response to intravenous Lasix in a dose of $20-60 \mathrm{mg}$., starting within 30 minutes and completed within 90 minutes to two hours, has made this method the ideal initial treatment in our experience for cases of acute pulmonary oedema. An oral dose of 120-200 mg. of Lasix given at the same time as the injection would ensure a prolongation of the diuresis. Vorburger (1964) recommends that the intravenous preparation be diluted in $10-15 \mathrm{ml}$. of $5 \%$ glucose and injected slowly over a period of one to two minutes. In our hands no local or general ill-effects have resulted from the rapid intravenous injection of Lasix in doses up to $60 \mathrm{mg}$. (three capsules of $20 \mathrm{ml}$.) undiluted.

The intramuscular route is effective and painless, should there be difficulty with veins and the patient be unable to swallow. Parenteral administration has been used abroad in patients with cerebral oedema, and in one of our patients proved most satisfactory in the "flushing" technique for the treatment of barbiturate overdosage (Lassen, 1960).

\section{Toxicity and Side-effects}

An efficient diuretic such as Lasix, used unnecessarily or in unwarranted dosage, might cause dehydration if fluid intake were restricted. Similarly, prolonged therapy combined with a low-sodium diet could result in hyponatraemia and a rising blood urea. The only side-effects noted by us were directly attributed to hypokalaemia-those in the two cases mentioned, one being a hepatic subject. It is particularly interesting that after massive diuresis, up to $6,735 \mathrm{ml}$., no patient has admitted to any weakness or languor (possibly owing to adequate potassium supplements) and no nausea, although in the same patients such symptoms, with occasional abdominal discomfort or diarrhoea, had been previously experienced after mersalyl. The only symptoms admitted on direct questioning after large outputs was some dryness of the mouth.

Neither instances of sensitization nor of blood dyscrasia have been observed. Rapid excretion would seem to preclude any accumulation, and, whereas impaired renal function adds a hazard to the use of some diuretics, a trial of Lasix carries no risk in oedematous patients with renal failure. Although claims of diuretic response in patients with blood urea levels of over $100 \mathrm{mg}$. have been made (Kiessling, 1964), we have not so far obtained a satisfactory result above $70 \mathrm{mg} . / 100 \mathrm{ml}$.

It may be concluded, therefore, that there are no adverse effects from this new preparation, apart from that possibility of hypokalaemia associated with massive outputs, particularly in patients with hepatic cirrhosis, or prolonged and unnecessary dosage.

\section{Summary}

A new potent and safe diuretic, 4-chloro- $N$-(2-furyl-methyl)5-sulphamoyl anthranilic acid, known in the United Kingdom as Lasix and elsewhere as Fursemide, has proved more effective than comparable standard doses of other diuretic agents, including hydrochlorothiazide.

Higher ranges of dosage increase the diuretic response; up to $300 \mathrm{mg}$. has been successfully used in cases of resistant oedema when mercurial diuretics and thiazides have failed.

The usual effective oral dosage is much lower and should be adjusted to the individual response. Potassium excretion is less during Lasix therapy than with thiazides in low and comparable dosage, but massive diuresis requires potassium supplementation, particularly in patients with hepatic cirrhosis.

Prompt diuresis by intravenous Lasix is of particular value in cases of acute pulmonary oedema. Parenteral therapy is also useful in the unconscious patient.

Experience over a period of 20 months with 80 patients, mostly in congestive heart failure, including four with ascites and oedema due to hepatic cirrhosis, warrants the opinion that this new diuretic is of great value.

We wish to thank Messrs. Hoechst Pharmaceuticals Ltd. for supplies of Lasix used in this trial; and our colleague, Dr. W. B. Thomson, for allowing us to quote one case under his care.

\section{REFERENCES}

1 Personal communications following the Symposium on Fursemide (Lasix) at Bad Homburg, December 1963: Bekaert, J. (Ghent); Deerzen, P. (Göttingen); Hutcheon, D. E. (Jersey City, N.J.); Deetzen, P. (Göttingen) ; Hutcheon, D. E. (Jiegen); Josephson, B. (Stockholm); Kuhlback, B. Janson, L. (Siegen); Josephson, B. (Stockholm); Kuhlback, B. (Helsinki) ; Schirmeister, J. (Freiburg); Suzuki, F., Klutsch, K., and
Heidland, A. (Würzburg) ; Vorburger, C. (Berne); Wolff, H. P., and Kruck, F. (Homburg).

Hutcheon, D. E., Mehta, D., and Leonard, G. B. (1964). Fed. Proc., 23,

439.
Karger, W., and Nagel, W. (1964). "Mode of Action of Different Pharmaceuticals on Cell Membranes." Paper read at the 28th Meeting of the German Physiological Society.

Kiessling, J. (1964). Münch. med. W schr. In press.

Kleinfelder H. (1963). Germ. med. Mih., 8, 459.

Klutsch, K., Heidland, A., and Suzuki, F. (1964). Atti. Accad. med. lombardia. In press.

Lassen, N. A. (1960). Lancet, 2, 338.

Lassen, N. A. (1960). Lancet, 2, 338. Reubi, F. C., and Cottier, P. T. (1961). Circulation, 23, 200.

Richterich, R. (1959). Klin. W schr., 37, 355 .

Scott, J., Emanuel, D., and Haddy, F. (1959). Amer. F. Physiol., 197, 305.

Sherlock, S., and Shaldon, S. (1963). Gut, 4, 95

Spencer, A. G. (1959). In Clinical Effects of Electrolyte Disturbance, edited by E. J. Ross, p. 50 . Pitman, London.

Taytor, F. F and Faloon, W. W. (1959). F. clin. Endocr., 19, 1683.

Ussing, H. H. (1949). Physiol. Rev., 29, 127.

Ussing, H. H. (1949). Physiol. Rev., 29, 1951. Acta physiol. scand., 23, 110

Vorburger, C. (1964). Rev. méd. Suisse rom., 84, 277. 